\title{
DEPENDENCES OF SMA MIXTURE AND ITS BITUMINOUS BINDER PROPERTIES ON BITUMEN BATCHING SYSTEM, MIXING TIME AND TEMPERATURE ON ASPHALT MIXING PLANT
}

\author{
Justas BRAŽIŪNAS ${ }^{\mathrm{a}}$, Henrikas SIVILEVIČIUSS ${ }^{\mathrm{a}}$, Romualdas VIRBICKAS ${ }^{\mathrm{b}}$ \\ ${ }^{a}$ Department of Transport Technological Equipment, Vilnius Gediminas Technical University, \\ Plytinés g. 27, 10105 Vilnius, Lithuania \\ ${ }^{b}$ PLLC "Fegda”, Lentvario g. 13, 02300 Vilnius, Lithuania
}

Received 13 May 2013; accepted 21 Jun 2013

\begin{abstract}
Bitumen holds the aggregate in hot mix asphalt (HMA). Without asphalt binder, HMA would simply be crushed stone or gravel. A bitumen batching system (BBS) is comprised of bitumen storage, transportation, weighing and discharge equipment in an asphalt mixing plant (AMP). The function of the equipment is to batch the binder heated up to working temperature and to discharge it into a mixer in batches. In the entire system, the binder is exposed to high temperature and oxygen. Bitumen is slowly oxidized when it is in contact with oxygen. The degree of oxidation is highly dependent on temperature, time and thickness of a bitumen film. This article models the key factors influencing on the dynamics of bitumen oxidation in BBS equipment. Stone mastic asphalt (SMA) mixture was produced from the same materials according to the same job-mix formula (JMF) in neighbouring batch type AMP by changing the mixing time of materials from 20 to $60 \mathrm{~s}$. Bitumen binder was separated from the taken SMA samples and its gradation was identified. Thus, Marshall specimens were produced and tested. Penetration $\mathrm{Pen}_{25}$ of bitumen binder recovered in rotary evaporator, softening point $T_{s p}$ was determined and penetration index $I_{p}$ was calculated. The presented findings of experimental investigation show that the properties of bitumen binder in BBS working at two different technologies changed inconsistently. Due to gravitation, the bitumen intensively flowing into a mixer (BBS1) is impacted by oxidation more than the bitumen batched by a high-pressure pump (BBS2).
\end{abstract}

Keywords: bitumen; hot mix asphalt (HMA); stone mastic asphalt (SMA); bitumen batching system (BBS); job-mix formula (JMF); oxidation, short-term ageing; rheology; penetration; viscosity; asphalt mixing plant (AMP).

Reference to this paper should be made as follows: Bražiūnas, J.; Sivilevičius, H.; Virbickas, R. 2013. Dependences of SMA mixture and its bituminous binder properties on bitumen batching system, mixing time and temperature on asphalt mixing plant, Journal of Civil Engineering and Management 19(6): 862-872. http://dx.doi.org/10.3846/13923730.2013.843587

\section{Introduction}

By volume, a typical HMA mixture is about $85 \%$ aggregate, $10 \%$ asphalt binder, and $5 \%$ air voids. Stone mastic asphalt (SMA) consists of coarse aggregates and a mastic of fine aggregate, mineral filler and asphalt binder. The mastic fills the voids between the coarse aggregates. The coarse aggregates interlock to form a stone skeleton. The bitumen is often reinforced with stabilizing agents such as small fibres or polymers. Because of the stone skeleton SMA mixture can provide a very stable and durable rut-resistant wearing course for highway applications (Lavin 2003).

Bitumens have very unusual engineering properties that must be carefully controlled in order to ensure good performance (Bražiūnas, Sivilevičius 2011). One of the most important characteristics of asphalt binders that must be addressed in test methods and specifications is that their precise properties almost always depend on their temperature. Asphalt binders tend to be very stiff and brittle at low temperatures, thick fluids at high temperatures, and leathery/rubbery semi-solids at intermediate temperatures.

Such extreme changes in properties can cause performance problems in pavements (Vislavicius, Sivilevicius 2013). At high temperatures, a pavement with a binder that is too soft will be prone to rutting and shoving. On the other hand, a pavement that contains a binder that is too stiff at low temperatures will be prone to lowtemperature cracking (Jenks et al. 2011).

Essentially, satisfactory performance of bitumen on the road can be ensured if four properties are controlled: rheology, cohesion, adhesion and durability. The rheology characteristics of bitumen at a particular temperature are determined by both constitution (chemical composi-

Corresponding author: Justas Bražiūnas

E-mail: justas.braziunas@vgtu.lt 
tion) and structure (physical arrangement) of the molecules in a material. Changes of constitution or structure or both will result in a change to the rheology (Read, Whiteoak 2003). Various mathematical equations, mostly Generalised Modified Sigmoidal Model, are applied to simulate rheological properties of unmodified and modified bitumens (Yusoff et al. 2013).

The chemical composition of bitumen is extremely complex; therefore, when conducting experimental investigations it is divided into two main fractions called asphaltenes and maltenes. Maltenes are resolved into saturates, aromatics and resins. The four groups are not well-defined and there is some overlap between the groups. However, this does enable bitumen rheology to be set against broad chemical composition (Redelius 2009). Four generic fractions play an inconsistent role in the temperature susceptibility of bitumens and the correlation degree of each fraction is somewhat different. The existence of aromatics and asphaltenes can lower the sensitivity to temperature changes whereas saturates and resins may have an adverse impact on the temperature susceptibility of bitumens. As for the correlation degrees, resins show the closest correlation with the temperature susceptibility of bitumens, then asphaltenes and aromatics, and the correlation between temperature susceptibility and saturates is relatively weak (Firoozifar et al. 2011; Liang et al. 2010). The physical properties of asphalt binder vary tremendously with temperature (Anderson 2011). Application of chemical composition mathematical models enables to identify viscoelastic properties of bitumen (Behzadfar, Hatzikiriakos 2013; Greenfield 2011).

Bitumen in common with many organic substances is affected by the presence of oxygen, ultraviolet radiation and by changes in temperature (Zhang et al. 2011; Huang, Zeng 2007). In bitumen, these external influences cause it to harden, resulting in a decrease in penetration $\left(P e n_{25}\right)$, an increase in softening point $\left(T_{s p}\right)$ and, usually, an increase in penetration index $\left(I_{p}\right)$. The most important mechanisms of bitumen hardening are: oxidation, volatilisation, steric or physical factors, and exudative hardening. Hardening due to oxidation has long been considered the main cause of ageing to the extent that other factors have been given scant consideration (Petersen, Glaser 2011). Polar groups containing oxygen are formed and these tend to associate into micelles of higher micellar weight thereby increasing the viscosity of bitumen (Greenfield 2011; Read, Whiteoak 2003). Oxidation intensity mostly depends on temperature (De Moraes et al. 2010) as well as the duration and intensity of contact with oxygen, thickness of bitumen film coating mineral fillers (Herrington 2012). Heating time and temperature have significant impact on bitumen rheological properties, such as viscosity, complex modulus, and creep stiffness (Dessouky et al. 2011). Tran et al. (2010), Huh and Robertson (1996) evaluated the prediction models of bitumen's critical high temperature on the properties of HMA mixture.
Ageing influenced bitumen chemistry and rheology significantly (Siddiqui 2010). However, chemical and rheological changes were generally not consistent, and consequently, ageing susceptibility of bitumens may be ranked differently when different evaluation methods are used ( $\mathrm{Lu}$, Isacsson 2002).

To reduce the deterioration of bitumen properties as much as possible and thereby to improve the properties of HMA mixture, the following additives of bitumen are used: antioxidants (Apeagyei 2011), modifiers (Haddadi et al. 2008), and adhesion enhancers. One of the prime roles of a bitumen modifier is to increase the resistance of the asphalt to permanent deformation at high road temperatures without adversely affecting the properties of bitumen or asphalt at other temperatures. Studies (Nien et al. 2008; Doğan, Bayramli 2009; Topal et al. 2011) have proved that the use of various polymer additives to improve the properties of the mixture is well-grounded. Polymer modification of asphalt binders has increasingly become the norm in designing optimally performing pavements, particularly in the United States, Canada, Europe and Australia. Specific polymers that have been used include rubber, SBR, SBS and Elvaloy (Yildirim 2007). Styrene-Butadiene-Styrene (SBS) triblock copolymer is commonly used for modifying physical, mechanical and rheological properties of bitumen (Słowik 2012).

The mechanism of adhesion between aggregates and bitumen should be understood to improve the lifetime of roads. The essential function of bitumen is to bind aggregates and to ensure the adhesion with the surface (Boulangé, Sterczynski 2012). Several parameters influence this adhesion: porosity and roughness of the aggregates, wettability between bitumen and aggregates and chemical composition at the interface (Bhasin, Little 2009; Horgnies et al. 2011). When producing mixtures with reclaimed asphalt pavement (RAP), aged and virgin bitumens are mixed. To maintain mechanical and physical properties of the recycled mixture, RAP quantity, homogeneity, mark of the aged and virgin bitumens, their penetration, quantity of virgin bitumen should be taken into account (Čygas et al. 2011; Baptista et al. 2013).

HMA mixture is produced by AMP of various structure and capacity, which use various technological schemes (Mogawer et al. 2012). A batch-type AMP has become most popular (Sivilevičius, Šukevičius 2009; Brown et al. 1989).

A complex value indicating the quality of HMA mixture produced by an AMP largely depends on the deviations of the content of HMA mixture components due to the errors in materials batching (White, Brown 1977; Brown et al. 1989; Stroup-Gardiner, Brown 2000; Sivilevičius, Vislavičius 2008). The improvement of material batchers at the enterprises producing HMA mixture allows not only decreasing the deviations of the amounts of HMA components from the values specified by jobmix formula (JMF) (Bražiūnas, Sivilevičius 2010), but also decreasing bitumen oxidation and increasing the 
reliability and durability of the equipment, as well as simplifying its control, maintenance and repair (Brock 1986).

The hardening of bitumen during spraying or stiffening of asphalt material that occurs during mixing and placement is called short-term ageing (Said 2005; Lund, Wilson 1984). All the aggregate and filler is coated with a thin film of bitumen usually between 5 and $15 \mu \mathrm{m}$ thick. Thus, when bitumen is mixed with hot aggregate and spread into thin films in an asphalt pugmill, conditions are ideal for the occurrence of oxidation and the loss of volatile fractions within the bitumen (Jemison et al. 1991). Hardening of bitumen during these processes is well known and is taken into account when selecting the grade of bitumen to be used. As a very rough approximation, during mixing with hot aggregates in a convention pugmill, the penetration of paving grade bitumen falls by about $30 \%$. However, the amount of hardening depends on a number of factors such temperature, mixing time, bitumen film thickness, etc. The minimisation of hardening during mixing depends on careful control of all these factors. Control of the temperature and the bitumen content are particularly critical. It could be stated that the BBS, in which bitumen ageing processes occur more slowly, is better.

Bitumen short-term ageing processes are investigated in scientific literature; however, experimental investigations proving the dynamics of these processes are scarce. The aim of the paper is to identify how bitumen properties change after its storage, transportation, batching and mixing processes in AMP. It also aims to compare the impact of BBS operating according to different technological schemes on the properties of bitumen binder and the produced SMA mixture.

\section{Impact of oxidation on bitumen properties}

The following technological production factors impact on the structure of the produced HMA mixture: temperature of materials and their weight in per cent in the mixture, the completion of bitumen conversion from volumetric state into a film; thickness and homogeneity of bitumen films coating the finest particles; mixing time and exposure of bitumen to ambient air oxygen, its surface area.

The key factor impacting on the lowest temperature of asphalt mixture is a necessity to obtain a required viscosity of bitumen. Liquid bitumen coats mineral particles properly and ensures the required resilience of HMA mixture when laying and compacting it. The temperature higher than that at which optimal viscosity of bitumen is obtained is not justified as it frequently deteriorates asphalt concrete exploitation properties. First of all, it is related with irreversible changes of bitumen structure and properties occurring due to thermal oxidation processes at high temperature. These processes rapidly speed up in the bitumen spread into thin films on mineral particles.

High temperature, at which bitumen integrates with aggregates, causes the change of its chemical composi- tion and structure, i.e. ageing of bitumen. The key factors influencing on the bitumen spread into a thin film are ambient air oxygen, high temperature, water and surface of an aggregate.

As explained above, a significant amount of bitumen hardening occurs during mixing and, to a lesser extent, during hot storage and transportation. However, hardening of the binder will continue on the road until some limiting value is reached. This behaviour is described as "long-term ageing" and is illustrated in Figure 1, which shows the ageing index of the bitumen after mixing, storage, transport, paving and subsequent service (Read, Whiteoak 2003; Apeagyei 2011).

Thermal oxidation ageing processes of various materials are described by the laws of kinetics of chemical reactions. The equation of the speed of these processes may be written as follows (Pecionyj 1990):

$$
\frac{d c}{d \tau}=k \cdot c^{e},
$$

where: $c$ - concentration of the material exposed to ageing in period $\tau ; k$-speed constant; $e$ - reaction order.

Due to the oxidation processes occurring in bitumen hydrocarbons and resins resulting in coarse components, a relative indicator of change in chemical composition of bitumen may be an increased content of asphaltenes.

Technological operations of mixing bitumen with aggregates are related with the impact of high temperature on bitumen resulting in oxidation processes in bitumen, which changes its chemical composition and structure (Kolbanovskaja, Michajlov 1973). An assumption could be made that bitumen oxidation speed varies at temperature according to Arrhenius (1887) equation, which relates reaction speed, activation energy and temperature:

$$
v=k \cdot e^{-\frac{E}{R T}}
$$

where: $v$ - speed of chemical reaction; $k$ - reaction speed constant; $E$ - activation relative reaction; $R$ - universal gas constant; $T$ - absolute temperature.

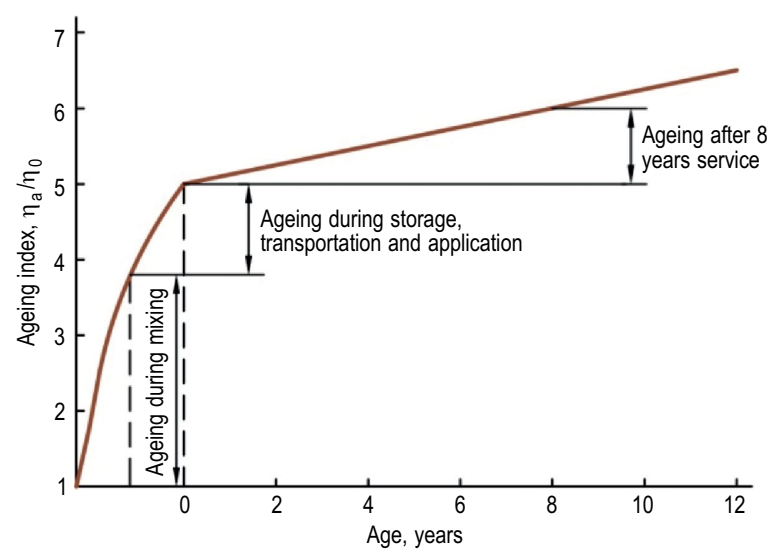

Fig. 1. Ageing of bitumen during mixing, subsequently during storage, transportation and application in service (Read, Whiteoak 2003) 
The results of bitumen ageing process may be evaluated by ageing index $I_{a}$ (Apeagyei 2011). Ageing index $I_{a}$ computations based on the single-point measurements are one of most common procedures used to estimate ageing and provide ranking among different asphalt binders. Ageing index is defined as the ratio of a given binder property after a given level of ageing to that before ageing, as shown in Eqn (3):

$$
I_{a}=\frac{\text { Physical property of aged bitumen }}{\text { Physical property of original bitumen }} .
$$

When mixed, particles of the aggregate are usually coated with a thin film of bitumen usually between 5-15 $\mu \mathrm{m}$ thick. When bitumen is in the condition of a thin film or a drop, the most active oxidation and volatilisation processes occur. It was determined that reducing the thickness of a bitumen film significantly increases the viscosity of the bitumen. The latter is measured by the ageing index, which is defined as the ratio of the viscosity of the aged bitumen $\eta_{a}$, to the viscosity of the virgin bitumen $\eta_{0}$. If the thickness of a film coating the particles of aggregate increases from $4 \mu \mathrm{m}$ to $10 \mu \mathrm{m}$, ageing index $I_{a}$ decreases from 7.0 to 5.5 (Read, Whiteoak 2003).

Viscosity is a fundamental property that describes the resistance of a liquid to deformation or flow based on the internal friction of its molecules. During manufacture and compaction of asphalt mixture, there are optimum bitumen viscosities. If the viscosity of the bitumen is too high during mixing, the aggregates will not be properly coated and if the viscosity is too low, the bitumen will coat the aggregate easily but may drain off the aggregate during storage or transportation. For satisfactory coating, the viscosity should be approximately 0.2 Pa-s (Pascalseconds).

Fluidity or viscosity is the primary consideration in pumping, transporting, and storing of bitumen. Viscosity is affected by temperature and by the type and grade involved. Figure 2 relates viscosity to temperature for four paving grades and two oxidized grades. Three lines indicating the approximate design pumpability, mixability, and sprayability are shown as well. At higher temperatures and lower viscosities, pumping is optimized;

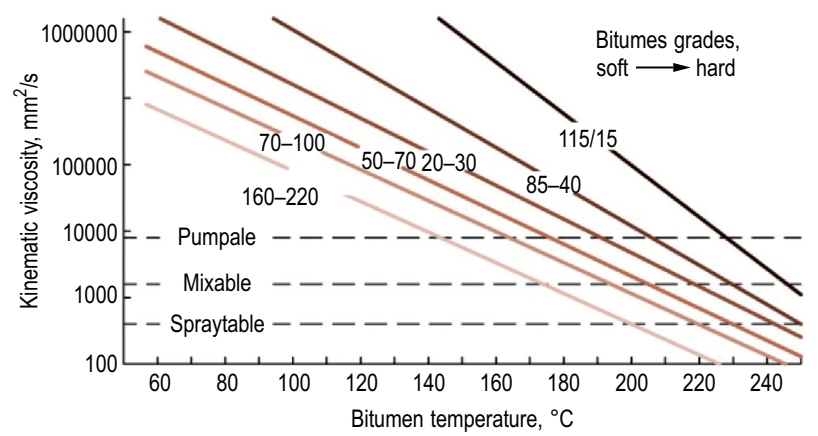

Fig. 2. Viscosity as a function of temperature for paving grade bitumen and for air-blown bitumen $\left(85^{\circ} \mathrm{C}\right.$ softening point and $110^{\circ} \mathrm{C}$ softening point). Design pumpability, mixability and sprayability (Sörensen, Wichert 2009) whereas at lower temperatures and higher viscosities pumping efficiency decreases rapidly. Thus, viscosity and its control by temperature is an important consideration in respect to all handling operations.

Theoretically, the thickness of a bitumen film may be calculated in several ways. In 1992, Hweem (Read, Whiteoak 2003) calculated surface area factors, assuming a spherical particle shape and a specific gravity of 2.65 :

$$
T=\frac{b}{100-b} \cdot \frac{1}{\rho_{b}} \cdot \frac{1}{S A F},
$$

where: $T$ is bitumen film thickness, $\mathrm{mm} ; \rho_{b}-$ density of bitumen, $\mathrm{kg} / \mathrm{m}^{3} ; S A F$ - surface area factor, $\mathrm{m}^{2} / \mathrm{kg}$ and $b$ - bitumen content, \% by weight.

Another method gives an approximation of the binder film thickness using Francaise formula used in 1991 (Read, Whiteoak 2003):

$$
T=\frac{b}{\frac{2650}{S G_{a}} \cdot \sqrt[5]{(0.25 G+2.3 S+12 s+135 f)}},
$$

where: $S G_{a}$ - density of the aggregate, $\mathrm{kg} / \mathrm{m}^{3} ; G$ - proportion by mass of aggregate over $6.3 \mathrm{~mm} ; S$ - proportion by mass of aggregate between $6.3 \mathrm{~mm}$ and $3.15 \mathrm{~mm}$; $s$ - proportion by mass of aggregate between $3.15 \mathrm{~mm}$ and $0.80 \mathrm{~mm}$; and $f$ - proportion by mass of aggregate smaller than $0.80 \mathrm{~mm}$.

Surface activating materials (surfactants, SAM), which impact on bitumen and aggregate surface molecular interaction processes, alleviate bitumen moistening and spreading on mineral surface. These two processes are two compulsory preconditions for the adhesion of the two materials. One of the methods enabling to improve bitumen moistening and spreading on the surface of aggregate is the reduction of its viscosity by increasing the temperature or diluting it with plastifiers. When temperature is reduced to $100{ }^{\circ} \mathrm{C}$, coating of mineral disperse material surface with bitumen is reduced.

\section{Experimental investigation}

\subsection{Bitumen batching systems analysis}

The Lithuanian asphalt concrete production company PLLC Fegda, where two batch type asphalt mixing plants (AMP) operate, was selected for the investigation. HMA mixture was produced in two different plants. AMP1 is newer and more modern technological equipment with the maximum capacity of $160 \mathrm{t} / \mathrm{h}\left(Q_{\max }=160 \mathrm{t} / \mathrm{h}\right)$, made in Germany; whereas AMP2 is older equipment made by the same manufacturer with the maximum capacity $Q_{\max }=240 \mathrm{t} / \mathrm{h}$. The equipment of these two AMP, which pump, transport, weigh and discharge bitumen into a mixer, differs as well.

BBS1 (Fig. 3) bitumen is pumped from storage tanks into a weigh bucket by Steimel TFE 10-240 rotary gear pump at the debit of 230-340 1/min.

The binder is transported to the weigh bucket 2 via $80 \mathrm{~mm}$ diameter pipe at the distance of approximately 


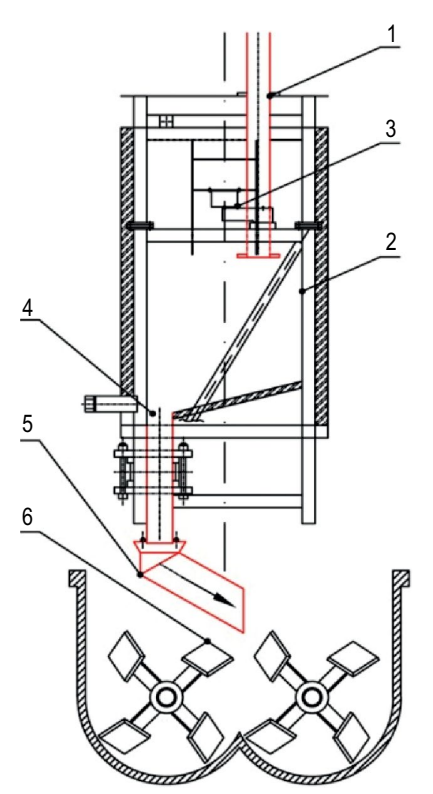

Fig. 3. A schematic view of major structural elements of bitumen batching system 1 (BBS1): incoming pipe (1); weigh bucket (2); weighing mechanism (3); outgoing pipe (4); batching pipe (5); mixer (6)

$50 \mathrm{~m}$. When a set amount of bitumen is pumped into the bucket, the weighing mechanism 3 sends information into the main computer, which switches the valve. The weighed out bitumen batch (138 $\mathrm{kg}$ according to JMF) flows through an outgoing pipe 4 and incoming pipe 5 at its own pressure from the weigh bucket into a mixer at one intensive turbulent flow (gravitational method).

BBS2 (Fig. 4) bitumen is pumped from storage tanks into the weigh bucket by the same rotary gear pumps. In the beginning of AMP exploitation of this system, only two bitumen storage tanks with separate transportation systems were used. Therefore, bitumen could be pumped into the weigh bucket via two pipes 1. Later, when there was a need to store 3-4 types of bitumen, this system was modernized. More storage tanks were built, and pumping pipelines were handled with automatic valves. BBS2 binder was transported about $8 \mathrm{~m}$ to bucket 2 .

When a required batch is weighed out, like in BBS1, bitumen flow is directed with a 3-position valve and bitumen flows in a closed system (remixing occurs). Sliding vane pump 5 Blackmer NP3 C sprays bitumen batched in weigh bucket 2 (201 $\mathrm{kg}$ according to JMF) into mixer 7 at the debit of approximately $5001 / \mathrm{min}$. via outgoing pipe 4 and spray bars 6 . The new AMP2 equipment contained original mixer spray bars with much smaller diameter holes allow to spray bitumen into a mixer in drops. The dusty environment used to glue those holes in a mixer, which protracted bitumen discharge into a mixer. Therefore, it was decided to shorten mixer spray bars and to enlarge spray holes at their ends so that they did not obstruct.

These two systems differ in the technology of discharging the weighed out bitumen. When weighed out bitumen is discharged at the high BBS1 debit flow into

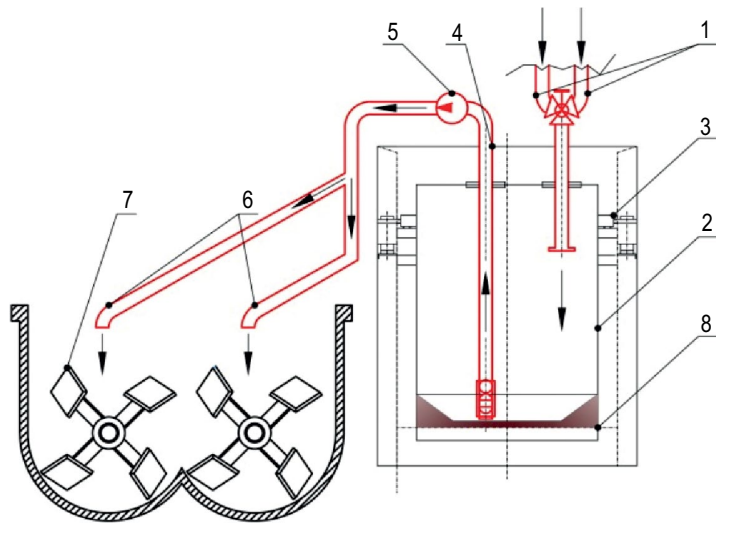

Fig. 4. A schematic view of major structural elements of bitumen batching system 2 (BBS2): incoming pipes (1); weigh bucket (2); weighing mechanism (3); outgoing pipe (4); pump for pumping the weighed out bitumen into mixer (5); mixer spray bars (6); mixer (7)

a mixer, the area of the binder's loose surface exposed to ambient air oxygen is smaller; therefore, there is a probability that it oxidizes less. When a bitumen batch is discharged into a mixer at high pressure in BBS2 of two small diameter pipes, it falls in sprays and has a larger surface area and, therefore, oxidizes more rapidly. So far, no investigation has been conducted to verify whether it is true.

\subsection{Used materials}

Bitumen storage tanks, from which the binder is transported via pipelines, are the same in AMP1 and AMP2, therefore, the assumption is made that PMB 45/80-55 bitumen used in the production of pilot SMA mixtures was transported of the same properties in both BBS1 and BBS2. When producing HMA mixture of the same composition in AMP1 and AMP2 from the same materials, its mixing time was changed. SMA $11 \mathrm{~S}$ mixtures were mixed with bitumen for 20,30, 40, 50 and 60 seconds in a mixer.

SMA $11 \mathrm{~S}$ mark HMA mixture for both AMP was produced according to the same job-mix-formula. The normative document The Lithuanian Specification of Technical Requirements for Automobile Road Asphalt Mixtures TRA ASFALTAS 08 regulates the requirements for each HMA mark gradation of the mixture. Lower $\left(L_{p}\right)$ and upper $\left(U_{p}\right)$ permitted technical tolerances of per cent passing are stipulated in TRA ASFALTAS 08, and those of the designed SMA $11 \mathrm{~S}$ mixture in a job-mix formula (JMF) (Fig. 5).

Optimal asphalt mixture gradation is determined through application of stochastic and deterministic optimization models (Sterling 2011; Sivilevičius et al. 2011). To produce SMA $11 \mathrm{~S}$ gradation mixture, granite screenings $(0 / 2 \mathrm{~mm})$, three fraction granite crushed stone $(2 / 5 \mathrm{~mm} ; 5 / 8 \mathrm{~mm} ; 8 / 11 \mathrm{~mm})$, activated mineral powder were used. Adhesion enhancing additive Iterlene and cellulose fibre additive $C P A$ were used in the mixture. 


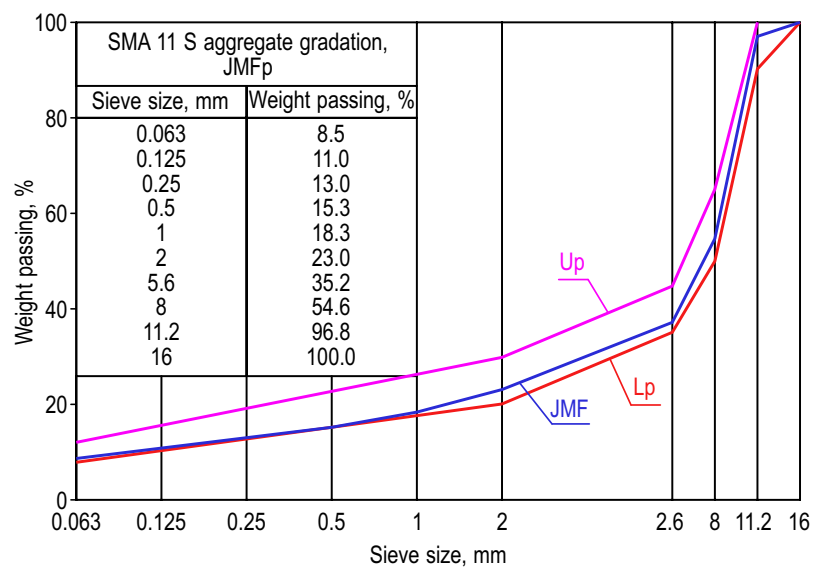

Fig. 5. SMA $11 \mathrm{~S}$ aggregate gradation $\left(\mathrm{JMF}_{\mathrm{p}}\right)$

By volume, SMA mixture was about $81.96 \%$ aggregate, $15.37 \%$ asphalt binder, and $2.7 \%$ air voids (test report No. 091049).

\subsection{Sample taking and testing}

Experimental investigation consists of two stages: mixture sample taking and sample testing in a laboratory. During the first stage of the experiment SMA mixture samples were taken and temperature was measured according to the procedures stipulated in standards. The produced SMA mixture was discharged from a mixer directly into a truck's body and not to storage silos. Therefore, its cooling, segregation and additional bitumen oxidation were avoided. All 10 samples, 5 from each AMP, taken according to standard LST EN 12697-27: 2002 (2002), when a mixture was mixed for $20,30,40,50$, $60 \mathrm{~s}$, were tested during the second stage in a certified laboratory.

The bitumen quantity and gradation were identified in asphalt samples. The rest of each sample was used to test Marshall specimen. Marshall stability, flow, Marshall quotient, maximum density, air void content, voids filled with bitumen (VFB), voids in mineral aggregate (VMA) were investigated. 10 samples of the bitumen extracted and recovered in rotary evaporator and the bitumen taken from a storage tank before production were tested as well. Bitumen sample penetration $\left(P{ }_{25}\right)$ and softening point $\left(T_{s p}\right)$ were identified and penetration index $\left(I_{p}\right)$ was calculated.

Pfeiffer and Van Doormaal (Read, Whiteoak 2003) 1936 wrote an equation for the temperature susceptibility that assumes a value of about zero for road bitumen. For this reason, they defined the penetration index $\left(I_{p}\right)$ as (Galooyak et al. 2010):

$$
I_{p}=\frac{1952-500 \cdot \log \left(P e n_{25}\right)-20 T_{s p}}{5 \cdot \log \left(P_{e n}{ }_{25}\right)-T_{s p}-120},
$$

where: $\mathrm{Pen}_{25}$ - the penetration at $25^{\circ} \mathrm{C}$ in $\mathrm{dmm}$ and $T_{s p}$ is the softening point of samples in ${ }^{\circ} \mathrm{C}$.

\section{Properties of the produced HMA mixture and bitumen}

Laboratory investigations showed that composition of HMA mixture produced in AMP1 and AMP2 varied inconsiderably and did not exceed tolerances from JMF value (except for the content of particles $>8 \mathrm{~mm}$ ) (Table 1).

Table 1. HMA mixture fraction composition and bitumen content

\begin{tabular}{|c|c|c|c|c|c|c|c|}
\hline \multirow{3}{*}{ Fraction } & \multicolumn{7}{|c|}{ Mineral component and bitumen content, $\%$} \\
\hline & \multirow{2}{*}{ JMF } & \multicolumn{5}{|c|}{ Mixing time $t_{m}, \mathrm{~s}$} & \multirow{2}{*}{$\begin{array}{l}\text { Max dev. } \\
\text { form JMF, } \\
\quad \pm \%\end{array}$} \\
\hline & & 20 & 30 & 40 & 50 & 60 & \\
\hline \multicolumn{8}{|c|}{ AMP1 } \\
\hline$>8$ & 45.4 & 48.8 & 57.4 & 52.0 & 50.6 & 50.6 & +12 \\
\hline$>5.6$ & 62.7 & 64.8 & 68.1 & 63.0 & 62.2 & 63.9 & +5.4 \\
\hline$>2$ & 77.0 & 76.7 & 77.6 & 75.7 & 75.8 & 75.9 & -1.3 \\
\hline $0.063-2$ & 14.5 & 14.0 & 13.4 & 14.3 & 14.9 & 14.6 & -1.1 \\
\hline$<0.063$ & 8.5 & 9.4 & 9.0 & 10.1 & 9.3 & 9.5 & +1.6 \\
\hline Bit. & 6.6 & 6.6 & 6.3 & 6.8 & 6.6 & 6.6 & -0.3 \\
\hline \multicolumn{8}{|c|}{ AMP2 } \\
\hline$>8$ & 45.4 & 53.1 & 47.5 & 43.8 & 52.3 & 53.4 & +8.0 \\
\hline$>5.6$ & 62.7 & 67.7 & 65.4 & 64.3 & 67.5 & 68.1 & +5.4 \\
\hline$>2$ & 77.0 & 77.2 & 76.5 & 76.1 & 77.3 & 76.9 & -0.9 \\
\hline $0.063-2$ & 14.5 & 14.8 & 15.1 & 15.3 & 14.8 & 14.1 & +0.8 \\
\hline$<0.063$ & 8.5 & 8.0 & 8.4 & 8.6 & 7.8 & 9.0 & +0.5 \\
\hline Bit. & 6.6 & 6.6 & 6.7 & 6.9 & 6.4 & 6.8 & +0.3 \\
\hline
\end{tabular}

The content of mineral powder (size $<0.063 \mathrm{~mm}$ ) in all HMA mixture samples produced in AMP2 was less than in those produced in AMP1. The weight passing in per cent of these particles differed from JMF within tolerance limits, i.e. it was less than $\pm 3 \%$. The weight in per cent of $>8 \mathrm{~mm}$ size and $>5.6 \mathrm{~mm}$ size aggregates in 9 out of 10 samples exceeded the amount set in JMF. The content of $>2 \mathrm{~mm}$ (coarse aggregate) and $0.063-2 \mathrm{~mm}$ (fine aggregate) in the produced SMA mixture deviated inconsiderably (the largest $-1.3 \%$ and $+0.8 \%$ ) from JMF requirements $( \pm 8.0 \%)$. The largest deviations of bitumen content in the produced SMA mixture $(-0.3 \%$ and $+0.3 \%)$ complied with tolerance requirements $( \pm 0.5 \%)$. It shows that SMA of the same component composition was produced in both AMP. It was only the SMA mixture mixed for $30 \mathrm{~s}$ in AMP1 that the quantity of particles larger than $8 \mathrm{~mm}$ varied by $+12.0 \%$ from JMF, i.e. it did not comply with the requirements of tolerances $( \pm 8.0 \%)$.

In AMP mixer the mixture is mixed at high working temperature (Grabowski et al. 2013), which is impacted by the aggregate heated in a drying and heating drum and bitumen heated in storage tanks. Taking into account that bitumen oxidation is mostly influenced by its temperature and the change of bitumen properties due to oxidation, it was important to identify the mixing temperature of the 
Table 2. HMA mixture production and samples temperature

\begin{tabular}{ccc}
\hline \multirow{2}{*}{$\begin{array}{c}\text { Mixing } \\
\text { time } \\
t_{m}, \mathrm{~s}\end{array}$} & $\begin{array}{c}\text { The arithmetic average of HMA mixture production } \\
\text { temperature in the AMP (computer data), }{ }^{\circ} \mathrm{C}\end{array}$ \\
\cline { 2 - 3 } 20 & AMP 1 & AMP 2 \\
\hline 30 & 173.1 & 174.0 \\
\hline 40 & 172.6 & 175.3 \\
\hline 50 & 184.5 & 177.5 \\
\hline 60 & 177.9 & 186.5 \\
\hline & 179.3 & 193.4 \\
\cline { 2 - 3 } & HMA mixture samples temperature, ${ }^{\circ} \mathrm{C}$ \\
\hline 20 & AMP 1 & AMP 2 \\
\hline 30 & 169 & 181 \\
\hline 40 & 171 & 171 \\
\hline 50 & 187 & 182 \\
\hline 60 & 192 & 196 \\
\hline
\end{tabular}

mixer. During the investigation, temperature displayed on the AMP handling computer and measured in situ (SMA samples taken from the truck's body) was analysed (Table 2).

Bitumen was stored in storage tanks at the temperature of $160{ }^{\circ} \mathrm{C}$. As the binder was pumped into AMP1 and AMP2 from the same capacity storage tank, it could be stated that its temperature after transportation via pipelines was approximately $160{ }^{\circ} \mathrm{C}$. It is more difficult to maintain stable temperature of aggregates. Due to their high volumetric content in the mixture, overheated aggregates may increase the total temperature of HMA mixture considerably. According to The Installation Rules of the Roads Pavement Asphalt Layers IT ASFALTAS 08, the temperature of SMA mixture produced with PMB 45/8055 mark binder will not be lower than $150{ }^{\circ} \mathrm{C}$ and not higher than $180^{\circ} \mathrm{C}$. Some asphalt mixture batches were of critical temperature or even exceeded it, which could speed up the oxidation processes. Dependence of change in bitumen quality parameters $\left(\mathrm{Pen}_{25}, T_{s p}\right)$ on mixture production temperature is described in regression equations (Fig. 6). The temperature of the mixture produced in AMP1 mixer influenced the change of bitumen penetration by approx. $90 \%\left(\mathrm{R}^{2}=0.902\right)$ and softening point by approx. $79 \%\left(\mathrm{R}^{2}=0.789\right)$. When the mixture was produced in an older AMP2 mixer, its bitumen penetration also decreased, and softening point increased; however, the impact of temperature was less than that in AMP1. The change of bitumen properties when the temperature of mixing the mixture in a mixer was increased from $172{ }^{\circ} \mathrm{C}$ to $187{ }^{\circ} \mathrm{C}$ was the same in AMP1 and AMP2. Therefore, it could be stated that the temperature of mixing SMA mixture in a mixer influenced on the change of bitumen properties due to its oxidation.

The findings of laboratory investigations of bitumen extracted from SMA $11 \mathrm{~S}$ mixture samples showed that the change of quality parameters $\mathrm{Pen}_{25}, T_{s p}, I_{p}$ of bitumen binder depends on BBS and mixing time $t_{m}$ (Fig. 7). a)

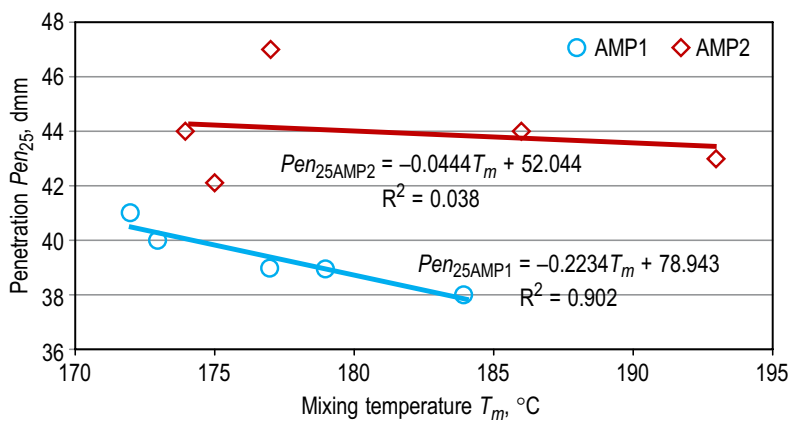

b)

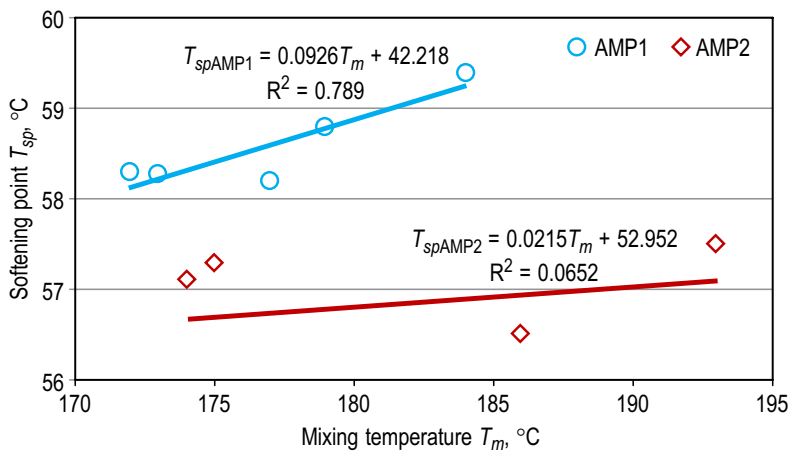

Fig. 6. Dependence of bitumen properties of the mixture produced in AMP1 and AMP2 on mixing temperature $T_{m}$ of HMA mixture: penetration $\left(\mathrm{Pen}_{25}\right)(\mathrm{a})$; softening point $\left(T_{s p}\right)(\mathrm{b})$

Various equation forms were used in regressive analysis and the description of the data obtained during experiments. The change of each indicator $\left(\mathrm{Pen}_{25}, T_{s p}\right.$, $I_{p}$ ) of the bitumen produced in both BBS when changing the mixing time of HMA mixture was described by curved-line regression equation with the highest determination coefficient $\mathrm{R}^{2}$. Pen 25 of the bitumen used in BBS decreased from its initial value of $48.7 \mathrm{dmm}$ to $39 \mathrm{dmm}$, when it was extracted from SMA mixture and recovered in rotary evaporator. The change of bitumen penetration $\mathrm{Pen}_{25}$ by approx. $95 \%\left(\mathrm{R}^{2}=0.946\right)$ was influenced by mixing time $t_{m}$ of SMA mixture.

Softening point $T_{s p}$ increased from its initial value of $55.0^{\circ} \mathrm{C}$ to $58.6^{\circ} \mathrm{C}$, and this change depends on mixing time by approximately $93 \%\left(\mathrm{R}^{2}=0.932\right)$.

The change of penetration $\mathrm{Pen}_{25}$ and softening point $T_{s p}$ of the bitumen used in BBS2 when increasing mixing time to $60 \mathrm{~s}$ was the same as that in BBS1. However, the change of these bitumen quality parameters was influenced only by $42-43 \%$ by mixing time $t_{m}$ of SMA mixture. More than $57 \%$ of their change depended on other factors outside regression equation, probably on temperature.

The calculated values of penetration index $I_{p}$ of the bitumen extracted from mixtures produced in AMP1 increased from its initial value of -0.1 to +0.26 AMP1 and up to +0.15 of the bitumen extracted from mixtures produced in AMP2.

When applying various BBS, the change of physical and mechanical properties of the produced SMA mix- 
a)

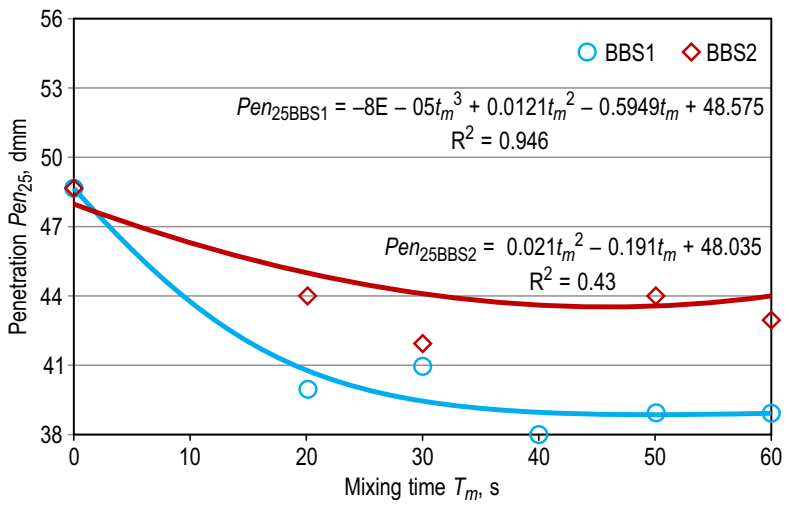

b)

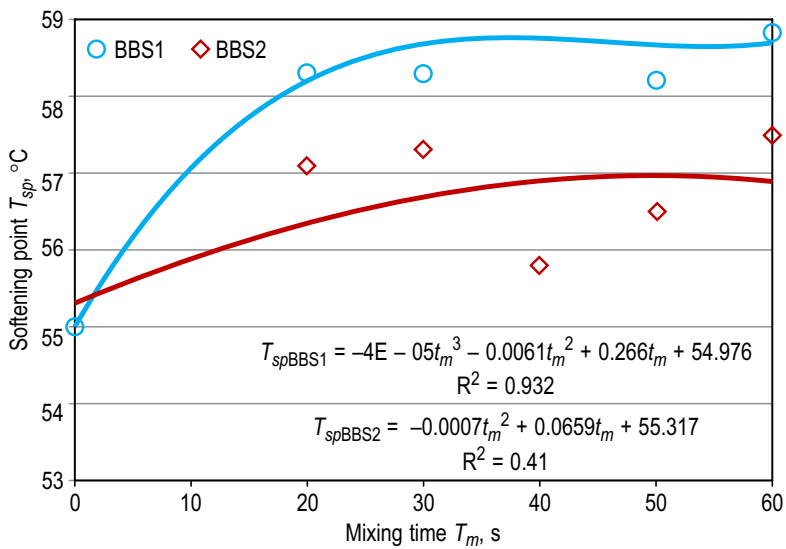

c)

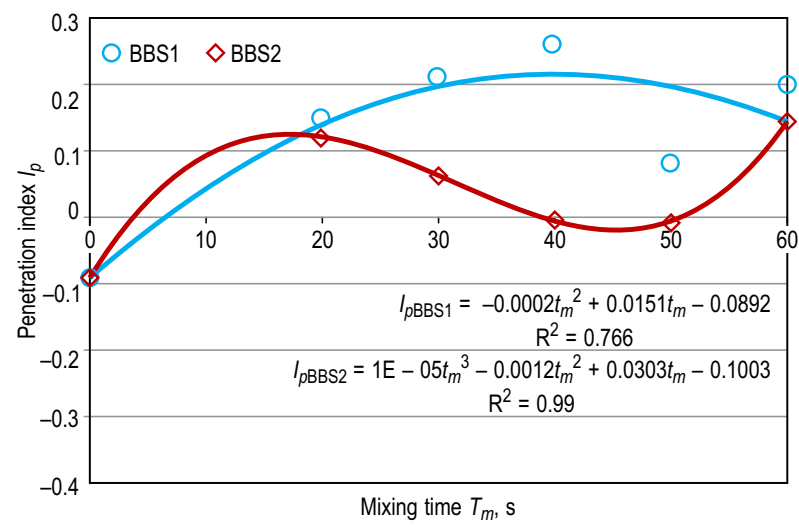

Fig. 7. Dependence of BBS1 and BBS2 batched bitumen properties on mixing time $t_{m}$ of HMA mixture: penetration $\left(P_{e n}\right)(\mathrm{a})$; softening point $\left(T_{s p}\right)(\mathrm{b})$; penetration index $\left(I_{p}\right)(\mathrm{c})$

ture was influenced not only by the method of bitumen discharge into a mixer, but by mixing time in it as well (Figs 8, 9). Physical HMA mixture parameters (maximum density and air void content) (Fig. 8) varied depending on mixing time. It was found that when mixing time was increased from 20 to $60 \mathrm{~s}$, maximum density increased and air void content decreased inconsistently. The impact of BBS construction on the physical parameters of SMA mixture was insignificant. The study showed that there is no clear correlation between voids filled with bitumen (VFB), voids in mineral aggregate (VMA) and AMP type and mixing time $t_{m}$.

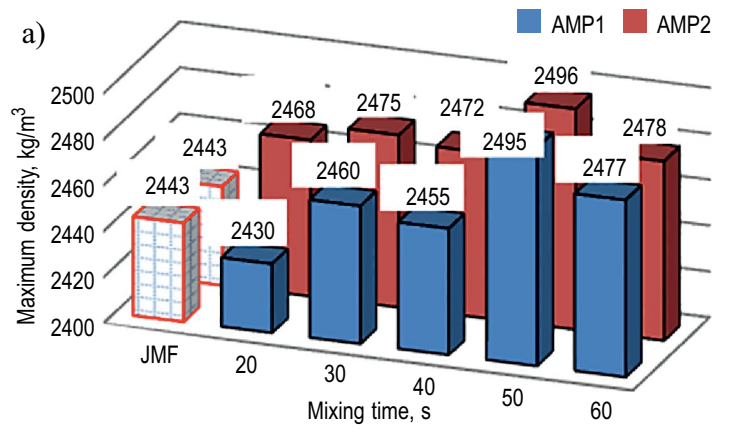

b)

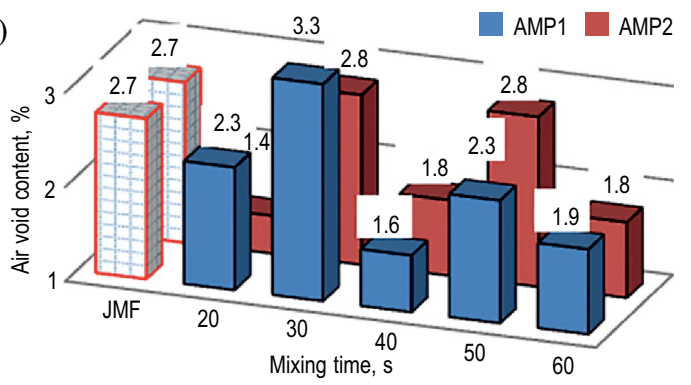

c)

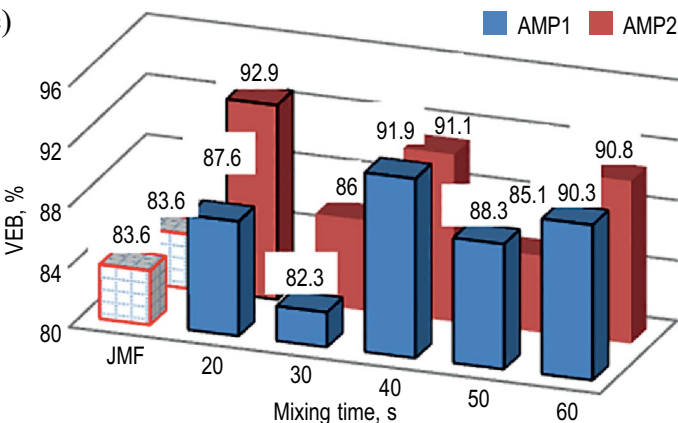

d)

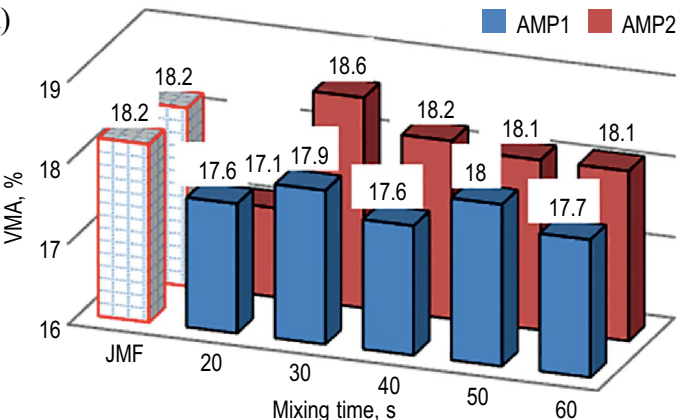

Fig. 8. Physical properties of HMA mixture: maximum density (a); air void content (b); VFB (c); VMA (d)

The aim to obtain higher HMA mechanical strength could be explained by two reasons. First, due to bitumen ageing processes: longer HMA mixing time increases its viscosity. Second, due to longer HMA mixing time, bitumen coats mineral particles better with a continuous film of the required thickness, which increases adhesion forces.

The oxidation process consisted of two stages: oxidation of bitumen discharged from a batcher into a mixer and oxidation during mixing. The longer the mixture is mixed, the longer is the oxidation process. The mixing process of AMP was the same; therefore, the differ- 
a)

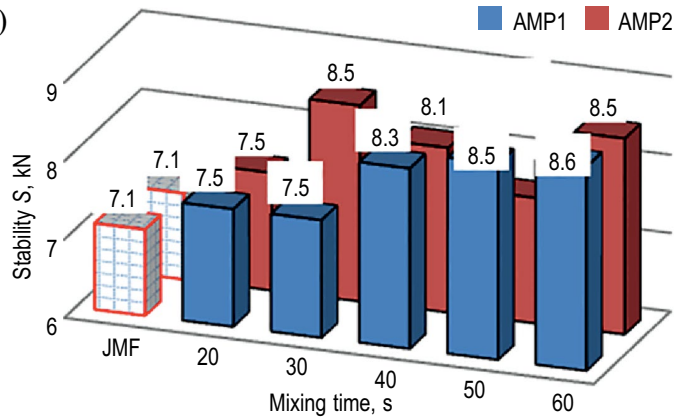

b)

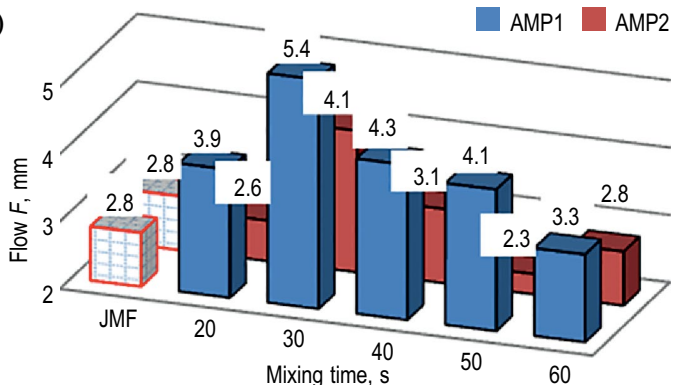

c)

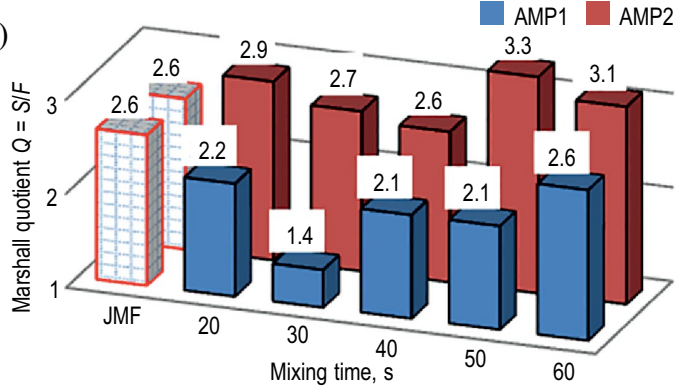

Fig. 9. Mechanical properties of HMA mixture: stability $S$ (a); flow $F(\mathrm{~b})$; Marshall quotient $Q$ (c)

ences in mixture strength properties may be explained by different bitumen ageing intensity when bitumen is discharged from a batcher into a mixer and different temperatures of SMA mixture.

It was found that longer mixing time increases HMA mixture stability and decreases flow (Fig. 9). When mixing time $t_{m}$ of SMA was increased, the content of loose bitumen decreased and the content of oriented bitumen increased, which coated a larger area of the surface of extremely fine particles. The Marshall quotient of SMA mixture produced in AMP 2 increased by $7 \%$ and that produced in AMP1 by $18 \%$.

Although it is difficult estimating the impact of the type of BBS, mechanical parameters of Marshall specimen show that the Marshall quotient of HMA mixture produced in AMP2 mixer was higher in all cases under investigation.

\section{Conclusions}

$I_{p}$ of the bitumen extracted from SMA mixture and recovered in rotary evaporator after batching in BBS1 and mixing in a mixer increases from -0.1 to $0.21-0.26 . I_{p}$ of the bitumen batched in BBS2 increases to 0.12-0.15. The bitumen extracted from the SMA mixture produced in AMP2 had better properties, i.e. smaller penetration variations were observed in all cases under investigation.

There was no evident change of bitumen binder properties extracted from HMA mixture when mixing time was increased to $60 \mathrm{~s}$. Within the range under investigation between $20 \mathrm{~s}$ and $60 \mathrm{~s}$, the highest reduction of bitumen penetration was identified when mixing time was $40 \mathrm{~s}$ in BBS1 and $30 \mathrm{~s}$ in BBS2.

It was identified that mixing time has an impact on the physical and mechanical properties of SMA mixture. Stability at longer mixing time increases from $7.5 \mathrm{kN}$ to $8.6 \mathrm{kN}$ of the mixture produced in AMP1 and from $7.5 \mathrm{kN}$ to $8.5 \mathrm{kN}$ of the mixture produced in AMP2. Flow tends to decrease when SMA mixture is mixed longer.

It was identified that during the processes of storage, weighing, dosing and mixing up to $60 \mathrm{~s}$, bitumen penetration decreases to $22 \%$. This results in a progressive increase in the stiffness modulus of the asphalt, together with a reduction in its stress relaxation capability. This will further increase the likelihood of pavement cracking and fretting.

Due to the increase of HMA mixture production temperature from $172{ }^{\circ} \mathrm{C}$ to $187^{\circ} \mathrm{C}$ in overheated aggregates, bitumen penetration fell from $41 \mathrm{dmm}$ to $38 \mathrm{dmm}$ in AMP1, and from $44 \mathrm{dmm}$ to $43 \mathrm{dmm}$ in AMP2. Softening point increased from $58^{\circ} \mathrm{C}$ to $59^{\circ} \mathrm{C}$ in $\mathrm{AMP} 1$, and from $56.5^{\circ} \mathrm{C}$ to $57{ }^{\circ} \mathrm{C}$ in AMP2.

Although the investigation has shown that different batching technologies impact on uneven bitumen short-term ageing, the impact of other parameters such as heat transfer between bitumen, aggregates and AMP equipment, bitumen and aggregate temperature will be investigated in further studies.

\section{References}

Anderson, R. M. 2011. The asphalt binder handbook, MS-26. $1^{\text {st }}$ ed. Lexington, KY: Asphalt Institute. 242 p.

Apeagyei, A. K. 2011. Laboratory evaluation of antioxidants for asphalt binders, Construction and Building Materials 25(1): 47-53.

http://dx.doi.org/10.1016/j.conbuildmat.2010.06.058

Arrhenius, S. 1887. Ueber die innere Reibung verdünnter wässeriger Lösungen, Zeitschrift fur Physicalisches Chemie I: 285-298. (in German).

Baptista, A. M.; Picado-Santos, L. G.; Capitão, S. D. 2013. Design of hot-mix recycled asphalt concrete produced in plant without preheating the reclaimed material, International Journal of Pavement Engineering 14(2): 95-102. http://dx.doi.org/10.1080/10298436.2011.587009

Behzadfar, E.; Hatzikiriakos, S. 2013. Viscoelastic properties and constitutive modelling of bitumen, Fuel 108: 391399. http://dx.doi.org/10.1016/j.fuel.2012.12.035

Bhasin, A.; Little, D. N. 2009. Application of microcalorimeter to characterize adhesion between asphalt binders and aggregates, Journal of Materials in Civil Engineering 21(6): 235-243.

http://dx.doi.org/10.1061/(ASCE)0899-1561(2009)21:6(235)

Boulangé, L.; Sterczynskia, F. 2012. Study of interfacial interactions between bitumen and various aggregates used in road construction, Journal of Adhesion Science and Technology 26(1-3): 163-173.

http://dx.doi.org/10.1163/016942411X569372 
Bražiūnas, J.; Sivilevičius, H. 2011. Statistical analysis of component content deviation from job-mix formula in hot mix asphalt, in Proc. of the 8th International Conference of Environmental Engineering, 19-20 May, 2011, Vilnius, Lithuania. Selected papers. Vol. 3. Vilnius: Technika, 2011, 1044-1050.

Bražiūnas, J.; Sivilevičius, H. 2010. The bitumen batching system's modernization and its effective analysis at the asphalt mixing plant, Transport 25(3): 325-335. http://dx.doi.org/10.3846/transport.2010.40

Brock, J. D. 1986. Oxidation of asphalt. Technical Paper T-103. Chattanooga: Astec Industries, Inc. 20 p.

Brown, E. R.; Collins, R.; Brownfield, J. R. 1989. Investigation of segregation of asphalt mixtures in the state of Georgia, in Transportation Research Record No. 1217, Asphalt Construction, Premature Rutting, and Surface Friction Courses, 1-8.

Čygas, D.; Mučinis, D.; Sivilevičius, H.; Abukauskas, N. 2011. Dependence of the recycled asphalt mixture physical and mechanical properties on the grade and amount of rejuvenating bitumen, The Baltic Journal of Road and Bridge Engineering 6(2): 124-134. http://dx.doi.org/10.3846/bjrbe.2011.17

De Moraes, M. B.; Pereira, R. B.; Simão, R. A.; Leite, L. F. M. 2010. High temperature AFM study of CAP 30/45 pen grade bitumen, Journal of Microscopy 239(1): 46-53. http://dx.doi.org/10.1111/j.1365-2818.2009.03354.x

Dessouky, S.; Reyes, Ch.; Ilias, M.; Contreras, D.; Papagiannakis, A. T. 2011. Effect of pre-heating duration and temperature conditioning on the rheological properties of bitumen, Construction and Building Materials 25(6): 2785-2792.

http://dx.doi.org/10.1016/j.conbuildmat.2010.12.058

Doğan, M.; Bayramli, E. 2009. Effect of polymer additives and process temperature on the physical properties of bitumen-based composites, Journal of Applied Polymer Science 113(4): 2331-2338. http://dx.doi.org/10.1002/app.30280

Firoozifar, S. H.; Foroutan, S.; Foroutan, S. 2011. The effect of asphaltene on thermal properties of bitumen, Chemical Engineering Research and Design 89(10): 2044-2048. http://dx.doi.org/10.1016/j.cherd.2011.01.025

Galooyak, S. S.; Dabir, B.; Nazarbeygi, A. E.; Moeini, A. 2010. Rheological properties and storage stability of bitumen/ SBS/montmorillonite composites, Construction and Building Materials 24(3): 300-307.

http://dx.doi.org/10.1016/j.conbuildmat.2009.08.032

Grabowski, W.; Jawowski, L.; Wilanowicz, J. 2013. Problems of energy reduction during the hot-mix asphalt production, The Baltic Journal of Road and Bridge Engineering 8(1): 40-47. http://dx.doi.org/10.3846/bjrbe.2013.06

Greenfield, M. L. 2011. Molecular modelling and simulation of asphaltenes and bituminous materials, International Journal of Pavement Engineering 12(4): 325-341. http://dx.doi.org/10.1080/10298436.2011.575141

Haddadi, S.; Ghorbel, E.; Laradi, N. 2008. Effects of the manufacturing process on the performances of the bituminous binders modified with EVA, Construction and Building Materials 22(6): 1212-1219.

http://dx.doi.org/10.1016/j.conbuildmat.2007.01.028

Herrington, P. R. 2012. Diffusion and reaction of oxygen in bitumen films, Fuel 94: 86-92. http://dx.doi.org/10.1016/j.fuel.2011.12.021

Horgnies, M.; Darque-Ceretti, E.; Fezai, H.; Felder, E. 2011. Influence of the interfacial composition on the adhesion between aggregates and bitumen: investigations by EDX, XPS and peel tests, International Journal of Adhesion and Adhesives 31(4): 238-247.

http://dx.doi.org/10.1016/j.ijadhadh.2011.01.005
Huang, S. C.; Zeng, M. 2007. Characterization of aging effect on rheological properties of asphalt-filler systems, International Journal of Pavement Engineering 8(3): 213-223. http://dx.doi.org/10.1080/10298430601135477

Huh, J.-D.; Robertson, R. E. 1996. Modeling of oxidative aging behavior of asphalts from short-term, high-temperature data as a step toward prediction of pavement aging, Transportation Research Record 1535: 91-97. http://dx.doi.org/10.3141/1535-12

Yildirim, Y. 2007. Polymer modified asphalt binders, Construction and Building Materials 21(1): 66-72. http://dx.doi.org/10.1016/j.conbuildmat.2005.07.007

Yusoff, N. I. Md.; Jakarni, F. M.; Nguyen, V. H.; Hainin, M. R.; Airey, G. D. 2013. Modelling the rheological properties of bituminous binders using mathematical equations, Construction and Building Materials (40): 174-188. http://dx.doi.org/10.1016/j.conbuildmat.2012.09.105

Jemison, H. B.; Davison, R. R.; Glover, C. J.; Bullin, J. A. 1991. Evaluation of standard oven tests for hot-mix plant aging, in Transportation Research Record No. 1323, Asphalt Mix Materials 77-84.

Jenks, C. W.; Jencks, C. F.; Harrigan, E. T.; Adcock, M.; Delaney, E. P.; Freer, H. 2011. NCHRP Report 673: A manual for design of hot mix asphalt with commentary. Washington, D.C.: Transportation research board of the National academies. 283 p.

Kolbanovskaja, A. S.; Mikhajlov, V. V. 1973. Dorozhnye bitumy. Moskva: Transport. 164 p. (in Russian).

Lavin, P. G. 2003. Asphalt pavements. London: Spon press. $444 \mathrm{p}$.

Liang, Y.; Feng, Z.; Yu, J. 2010. Effect of chemical compositions on temperature susceptibility of bitumens, Journal of Wuhan University of Technology - Materials Science Edition 25(4): 669-673. http://dx.doi.org/10.1007/s11595-040-0067-2

LST EN 12697-27:2002 Bituminiai mišiniai. Karštojo asfalto mišinio bandymo metodai. 27 dalis. Eminiu èmimas [Bituminous mixtures - Test methods for hot mix asphalt - Part 27: Sampling]. Vilnius: Lithuanian Standards Board. $17 \mathrm{p}$.

Lu, X.; Isacsson, U. 2002. Effect of ageing on bitumen chemistry and rheology, Construction and Building Materials 16(1): 15-22. http://dx.doi.org/10.1016/S0950-0618(01)00033-2

Lund, J. W.; Wilson, J. E. 1984. Evaluation of asphalt aging in hot mix plants (with discussion), in Proc. of Annual Meeting of the Association of Asphalt Paving Technologists, 9-11 April, 1984, Scottsdale, Arizona, 1-18.

Mogawer, W. S.; Austerman, A. J.; Bonaquist, R. 2012. Determining the influence of plant type and production parameters on performance of plant-produced reclaimed asphalt pavement mixtures, Transportation Research Record 2268: 71-81. http://dx.doi.org/10.3141/2268-09

Nien, Y. H.; Yeh, P. H.; Chen, W. C.; Liu, W. T.; Chen, J. H. 2008. Investigation of flow properties of asphalt binders containing polymer modifiers, Polymer Composites 29(5): 518-524. http://dx.doi.org/10.1002/pc.20404

Pecionyj, B. G. 1990. Bitumy i bitumnye compozitsii. Moskva: Chimiia. 156 p. (in Russian).

Petersen, J. C.; Glaser, R. 2011. Asphalt oxidation mechanisms and the role of oxidation products on age hardening revisited, Road Materials and Pavement Design 12(4): 795819. http://dx.doi.org/10.1080/14680629.2011.9713895

Read, J.; Whiteoak, D. 2003. The Shell bitumen handbook. $5^{\text {th }}$ ed. London: Thomas Telford Ltd. $464 \mathrm{p}$.

Redelius, P. 2009. Asphaltenes in bitumen, what they are and what they are not, Road Materials and Pavement Design 10(sup1): 25-43. http://dx.doi.org/10.1080/14680629.2009.9690234 
Said, S. F. 2005. Aging effect on mechanical characteristics of bituminous mixtures, Transportation Research Record 1901: 1-9. http://dx.doi:10.3141/1901-01

Siddiqui, M. N. 2010. NMR fingerprinting of chemical changes in asphalt fractions on oxidation, Petroleum Science and Technology 28(4): 401-411. http://dx.doi.org/10.1080/10916460903070751

Sivilevičius, H.; Podvezko, V.; Vakrinienè, S. 2011. The use of constrained and unconstrained optimization models in gradation design of hot mix asphalt mixture, Construction and Building Materials 25(1): 115-122. http://dx.doi.org/10.1016/j.conbuildmat.2010.06.050

Sivilevičius, H.; Šukevičius, Š. 2009. Manufacturing technologies and dynamics of hot-mix asphalt mixture production, Journal of Civil Engineering and Management 15(2): 169-179. http://dx.doi.org/10.3846/1392-3730.2009.15.169-179

Sivilevičius, H.; Vislavičius, K. 2008. Stochastic simulation of the influence of variation of mineral material grading and dose weight on the homogeneity of hot-mix asphalt, Construction and Building Materials 22(9): 2007-2014. http://dx.doi.org/10.1016/j.conbuildmat.2007.07.001

Słowik, M. 2012. Modelling of the inverse creep of road bitumen modified with SBS copolymer, The Baltic Journal of Road and Bridge Engineering 7(1): 68-75. http://dx.doi.org/10.3846/bjrbe.2012.10

Sörensen, A.; Wichert, B. 2009. Asphalt and bitumen, in Ullmann's encyclopedia of industrial chemistry. Weinheim: Wiley-VCH Verlag GmbH \& Co. KgaA, 273-294. http://dx.doi.org/10.1002/14356007.a03 169.pub2

Sterling, V. A. 2011. A manual for design of hot mix asphalt with commentary. NCHRP Report 673. Washington, D. C.: Transportation Research Board. 273 p.
Stroup-Gardiner, M.; Brown, E. R. 2000. Segregation in hotmix asphalt pavement. NCHRP Report 441. Washington, D.C.: Transportation research board of the National academies. 95 p.

Topal, A.; Yilmaz, M.; Kok, B. V.; Kuloglu, N.; Sengoz, B. 2011. Evaluation of rheological and image properties of styrene-butadiene-styrene and ethylene-vinyl acetate polymer modified bitumens, Journal of Applied Polymer Science 122(5): 3122-3132. http://dx.doi.org/10.1002/app.34282

Tran, N.; Taylor, A. J.; West, R. C.; Kvasnak, A.; Turner, P. 2010. Evaluation of predictive models for determination of binder critical high temperature from mixture properties, in TRB 89th Annual Meeting Compendium of Washington, D.C.: Transportation research board of the National academies. Papers DVD.

Vislavicius, K.; Sivilevicius, H. 2013. Effect of reclaimed asphalt pavement gradation variation on the homogeneity of recycled hot-mix asphalt, Archives of Civil and Mechanical Engineering 13(3): 345-353. http://dx.doi.org/10.1016/j.acme.2013.03.003

Zhang, H. L.; Yu, J. Y.; Xue, L. H.; Li, Z. C. 2011. Effect of montmorillonite organic modification on microstructures and ultraviolet aging properties of bitumen, Journal of Microscopy 244(1): 85-92. http://dx.doi.org/10.1111/j.1365-2818.2011.03511.x

White, T. D.; Brown, E. R. 1977. Statistical quality control procedures for airfield pavement materials and construction, Transportation Research Record 652: 36-42.

Justas BRAŽIŪNAS. Junior research fellow and doctoral student at the Department of Transport Technological Equipment of Vilnius Gediminas Technical University, Lithuania. Research interests: technologies of hot mix asphalt mixture production, bitumen storage, heating, pumping, metering and batching systems of the asphalt mixing plants, bitumen and hot mix asphalt ageing.

Henrikas SIVILEVIČIUS. Dr Habil, Professor at the Department of Transport Technological Equipment of Vilnius Gediminas Technical University, Lithuania. Research interests: flexible pavement life-cycle, hot mix asphalt mixture production technology, application of statistical and quality control methods, recycling asphalt pavement technologies and design, decision-making and expert systems theory.

Romualdas VIRBICKAS. Quality Control manager of JSC „Fegda“, Vilnius. Research interests: research and application of new technologies of roads, urban streets and airport pavements construction, design of roads, urban streets and airport pavements, project and structure inspection, maintenance inspection of roads and urban streets. 